\title{
SHAPING METHOD ECOSYSTEMS - STRUCTURED IMPLEMENTATION OF SYSTEMS ENGINEERING IN INDUSTRIAL PRACTICE
}

\author{
Inkermann, David \\ Technische Universität Clausthal
}

\begin{abstract}
Systems thinking is vital for engineering of nowadays systems characterized by system spanning interactions and an incresing amount of functions. Systems Engineering (SE) represents an interdisciplinary approach, gaining extensive attention to cope with increasing system complexity. Implementation of SE in existing organizations and processes, however, is facing challenges. As a matter of course there is not out of the box concept to be used, in fact definitions and understandings seem to be based on the background and experience of the individual or organization und differ widely. Thus, motivations and expectations of practitioner are manifold and support to adapte and implement SE-methodolgies is needed. Research presented in this contribution picks up the need to provide orientation for individuals, engineering teams and project managers when implementing SE and to address the specific context in that engineering is carried out. Objective is to describe the core idea of SE by a consistent set of principles. This set is used to build up a context specific understanding of SE as a foundation to introduce new methods and procedures in existing method ecosystems.
\end{abstract}

Keywords: Systems Engineering (SE), Design methods, Design education, Design process

\section{Contact:}

Inkermann, David

Technische Universität Clausthal

Institute for Mechanical Engineering

Germany

inkermann@imw.tu-clausthal.de

Cite this article: Inkermann, D. (2021) 'Shaping Method Ecosystems - Structured Implementation of Systems Engineering in Industrial Practice', in Proceedings of the International Conference on Engineering Design (ICED21), Gothenburg, Sweden, 16-20 August 2021. DOI:10.1017/pds.2021.525 


\section{INTRODUCTION AND BACKGROUND}

Across industries, engineering teams are struggling to handle the complexity of nowadays systems characterised by system spanning interactions and increasing amount of functions. For this reason, the need for new methods in engineering appears to be greater than ever before. Systems Engineering (SE) is gaining attention as a capable approach to treat the rising complexity of systems and processes. However, implementation of SE in existing organizations and engineering projects is facing challenges. As a matter of course there is not out of the box concept that can be used by practitioner. In fact, definitions and understandings are based on the background and experience of the individual or organization and differ widely (Blanchard and Fabrycky, 1998). In consequence, motivations and expectations of practitioner are manifold and clash with a lack of structured support to adapt and implement SE-methodologies. Challenges like the transformation of organizational structures (Huldt and Stenius, 2019; Friedenthal, 2014), a lack of methods to introduce SE (Gausemeier et al., 2015), and a diffuse understanding of $S E$ itself are frequently reported. Looking at these challenges in more detail, it turns out that there is a correlation with hurdles in the transfer of methods discussed in the engineering design community for years, e.g. (Wallace, 2011; Birkhofer et al., 2002; Gericke et al., 2020). In this paper we presume, that there are two essential hurdles to overcome to introduce SE in industrial practice: 1) the diffuse understanding of SE and 2) an isolated view on methods as a single issue. To overcome the hurdles, the concept of method ecosystems, c.f. (Gericke et al., 2020), is proposed to characterise design methodologies and adapt existing and integrate new methods in current processes and organizations. The contribution aims at giving insight on how method ecosystems can be shaped focussing on the principles characterising SE.

\subsection{Fundamentals of Systems Engineering}

The history of SE is e.g. outlined by Hossain et al. (2020) and is shaped by works in the (American) aerospace and defence industry. Due to the different perspectives, there is neither a uniform definition of terms nor a uniform methodology for SE (Estefan 2007). It is common sense that the general system theory and the general model theory are fundamentals of all SE methodologies. Moreover, SE integrates the domains of system design and project management to achieve an optimal balance of all system elements (Martin, 1997; Haberfellner et al., 2019). Haberfellner et al. (2019) highlight the need to integrate techniques from both domains into a SE-mind-set and establish System Thinking and SEprocedures. The SE mind-set includes two principles, namely the system-of-system principle (SoS) and the system-of-interest principle (SoI). These principles are picked up in various methodologies and serve as a basis for model-based systems engineering (Lohmeyer and Albers, 2012). It has to be stated, that there is often insufficient differentiation and connection of SE and established domain specific engineering. This complicates the practical implementation of SE. Based on the V-Model Forsberg and Mooz (1992) and Buede (2009) provide a coherent link of SE and domain specific engineering. SE covers the upper part of the V-Model focussing on system definition and decomposition (left hand side) as well as integration and verification of modules, subsystems and systems (right hand side). SE activities have to provide specifications the domain specific engineering of subsystems and modules. To define primary activities various process models are proposed. A prominent example defining a logical sequence of tasks to be performed are the ISO 15288 and its adaptions, see e.g. Walden et al. (2015). These models describe phases and activities of engineering projects on a strategical level and define information artefacts to be delivered. Insights on how to perform these activities are given by more operational methodologies like the FAS methodology (Lamm and Weilkiens, 2010). These methodologies propose methods and modelling techniques for single phases and actions and specify information artefacts to be delivered from a technical point of view.

\subsection{Key Terms and their Interactions}

It is important to establish the terminology associated with methodology, processes, methods, and tools to map this research into the fabric of SE, as well as to face the increasing multidisciplinary in industrial practice and research. Literature has bearded a numerous concepts and frameworks to define and interrelate key terms like methodology, process, method or tool. In the context of SE Estefan (2008) defines a methodology as "a collection of related processes, methods, and tools". Gericke et al. (2017) focus on the role and understanding of methods in the engineering design community and propose a consolidated terminology for the terms methodology, process, method, tool, and guideline, see Figure 1. The definitions proposed by Gericke et al. (2017) are picked up here and are complemented by the term 
principle. Principles are introduced to express the core ideas underlying the structure of a process, a method or a guideline and thus a methodology. The distinction between a guideline and a principle is based on the validity for different disciplines, time spans and methodologies. A principle defines the percept of how to organise a sequence of design activities (process) or describes the basic idea and technique a method is based on. It is expected, that principles remain valid, even if a great part of the environment a process or a method is performed in changes (Emes et al., 2012). Due to their vital character, principles are also seen as means to overcome the differing semantics in disciplines (Kossiakoff et al., 2011). Aside from the process domain, there are principles focussing on the product domain. Here principles give references on how to design the product or focus on single properties (Design for X). The interactions of the key terms introduced is represented in Figure 1.

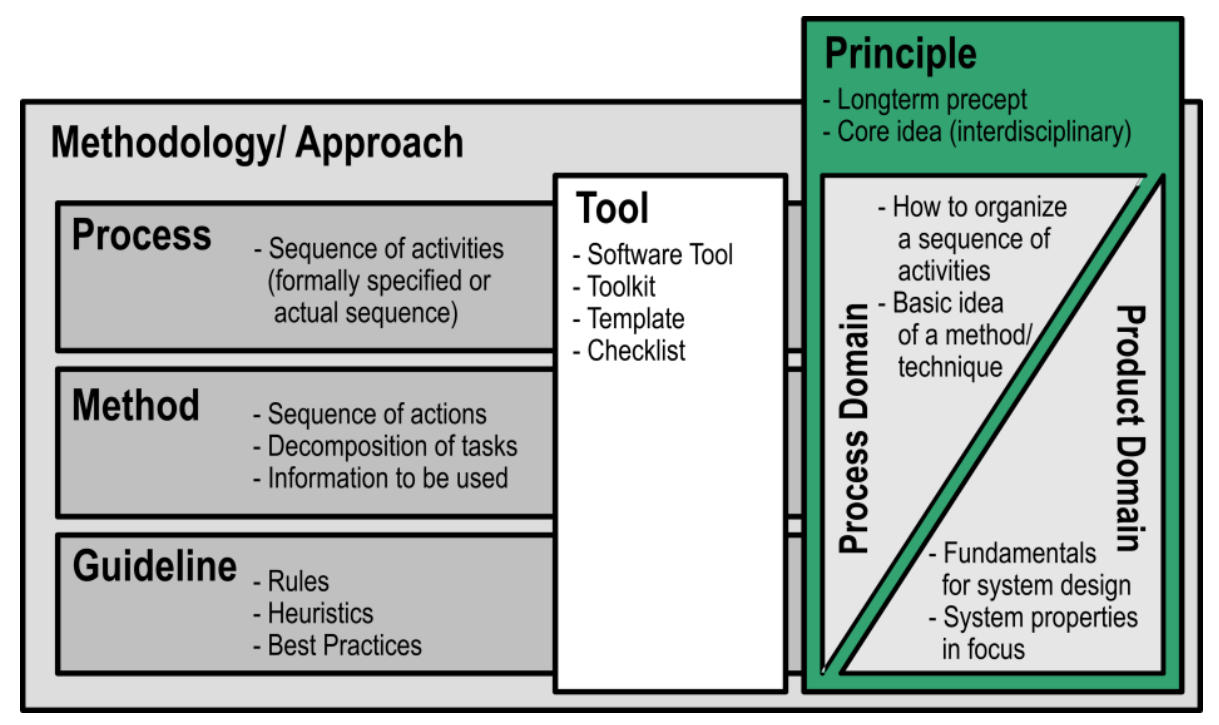

Figure 1. Core Terms and Their Interrelations for Research into Structured Implementation of Systems Engineering Methods. for Definitions of the terms Methodology, Process, Method, Guideline, and Tool see Gericke et al. (2017)

Principles are valid for different methodologies and thus can be used to describe the basic mind-set and fundamentals for engineering. In line with the understanding of Estefan (2008), a methodology is seen as an approach involving a set of processes, methods, guidelines, and tools, see Figure 1. Thus, SE is a methodology, involving different processes, methods, and tools and following a set of guidelines.

\subsection{Ecosystems of Methods}

Methods are core elements of design methodologies aiming to support designers when performing their tasks and in achieving the results specified. A method includes specifications on what actions to be performed, how to represent information, what information to use as inputs, which tools to use, and how to decompose tasks and sequence actions (Gericke et al., 2017). However, it is important to consider design methods as parts of a system comprising further methods, method users, and the organization and its processes. Gericke et al. (2020) therefore propose the term ecosystems of methods. An ecosystem of methods is defined as a system of methods embedded in an organization, where different design methods are used in conjunction and where users are able to adapt and connect different methods with regard to the given tasks. Main characteristics are, c.f. (Gericke et al., 2020):

- Ecosystems of methods do not comprise a fixed set of methods, methods can be added and methods can be substitute for different tasks.

- Ecosystems of methods provide a structure in which methods can or should be used but do define a strict sequence of methods.

- Ecosystems of methods evolve over time, since researchers and practitioner move between organisations and boundary conditions change.

Method ecosystems imply a communality in terminologies and a certain degree of stability with regard to structure and methods used. Terminology and stability for instance refer to an academic discipline, an industry or a company, thus multiple ecosystems of methods exist at the same time and can overlap. The concept of ecosystems of methods here is picked up focussing on the individual context of method application and the implementation of SE methodologies in industrial practice. 


\subsection{Objective and Methods of Research}

This research is driven by challenges of implementing SE methodologies and suitable methods in industrial practice. The aim is to understand the ecosystem of SE-methods and to support shaping of existing ecosystems by addressing the designer's individual context and engineering tasks. The scope of this research is driven be the following research question:

How can SE-principles be used for goal setting and identification of suitable methods to shape existing ecosystems of methods in industrial practice?

Following this question, main objectives are 1) to support the identification of methods suitable to implement the core ideas of SE and 2) to determine required adaptions of processes, tools and organisation when integrating the new methods. Therefore, in a first step a set of principles (SEPrinciples) is formulated based on a literature review see section 2. The SE-Principles are expected to give individual guidance when shaping the ecosystem of SE methods. In the second step, a procedure and tools are proposed for structured analysis of the existing method ecosystem and identification of suitable SE-methods and required adaptions in a workshop scenario see section 3. Section 4 concludes the paper by naming the essential contributions and limitations.

\section{SE-PRINCIPLES - COMMON GROUNDING TO IMPLEMENT SE-METHODS}

This section presents the results of an initial literature review and clustering analysis to derive common principles characterising the methodology of SE. The principles introduced do not focus on the design and architecture of the system but aspects to be considered when planning, organising, performing, and controlling technical development.

\subsection{Principles describing character, approach and objectives of SE}

To formulate principles forming the common ground of SE methodologies, definitions, approaches, and objectives described in literature have been analysed. Basic aim of the analysis was to identify recurring statements of how to organise a sequence of design activities (process) or basic ideas and techniques methods are based on, c.f. definition of principle in subsection 1.2.

\subsubsection{Literature review}

The review includes established textbooks, frequently cited papers and standards used in the research community and for education in SE. Using the term systems engineering the google scholar database were searched and the results reviewed against two criteria:

- The references have to follow an overall system perspective on SE and do not focus a single engineering or management disciplines like software systems engineering or project management

- The references are addressing the entire engineering process do not focus on single activities or phases like requirements engineering

In addition, only references with a minimal number of 100 citations were considered. Twenty references (textbooks and papers) and three standards were identified for the initial analysis, c.f. Figure 2. These works contain at least one definition or explanation of SE. In most of the references a concept and understanding of SE is described in detail, naming aspects to distinguish SE from traditional engineering e.g. Kossiakoff et al., (2011) describing key issues of SE e.g. Martin (1997), and highlighting special areas of emphasis (Blanchard and Fabrycky, 1998). In some of the works already, principles are formulated. Wymore (1993) for instance describes roles to follow when applying SE and Shread and Mostashari (2009) name roles that should be followed when working as a systems engineer. Frank (2000) define principles for structuring and designing in SE and Boehm et al. (2007) describe key process principles to address the challenges of engineering processes. To derive characteristics of SE the references listed in Figure 2 were analysed regarding keywords and statements that specify the nature of SE. This analysis ware carried out manually by identifying key words within the given explanations, definitions or principles described in the references. To overcome differences in semantics in a second step eight characteristics were defined for clustering. For instance, references stating, "Systems Engineering is a multidisciplinary approach for developing solutions for complex engineering problems" (Friedenthal, 2014) were assigned to the characteristic SE is based on interdisciplinary. Figure 2 summarizes the characteristics derived from the analysis and indicates the overall ratings for each characteristic. Based on the analysis a clustering was performed and detailing principles defined. 


\begin{tabular}{|c|c|c|c|c|c|c|c|c|c|c|}
\hline \multirow[b]{2}{*}{ No. } & \multirow[b]{2}{*}{ Reference (see References in this paper) } & \multirow[b]{2}{*}{\begin{tabular}{|c|} 
Number of \\
Citations
\end{tabular}} & \multicolumn{8}{|c|}{ Characteristics directly addressed in the references } \\
\hline & & & 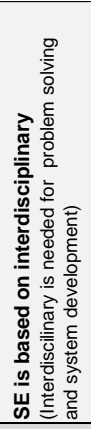 & 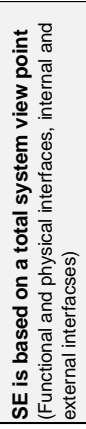 & 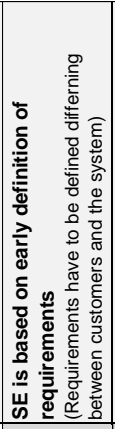 & 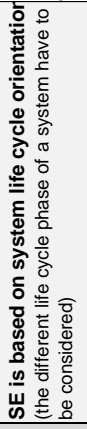 & 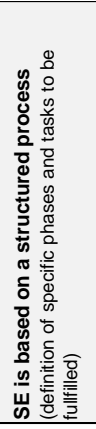 & 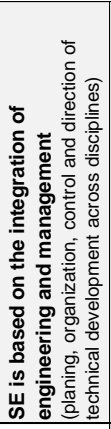 & 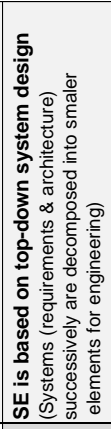 & 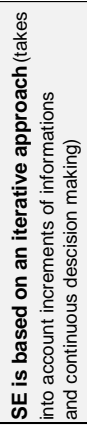 \\
\hline 1 & Blanchard, B. S. \& Fabrycky, W. J., 1990 & 3509 & $\bullet$ & & $\bullet$ & $\bullet$ & & & $\bullet$ & \\
\hline 2 & Friedenthal et al., 2014 & 1740 & $\bullet$ & - & & & & $\bullet$ & & \\
\hline 3 & Buede \& Miller, 2009 & 1266 & $\bullet$ & & $\bullet$ & $\bullet$ & & & $\bullet$ & \\
\hline 4 & Hall, 1962 & 1163 & $\bullet$ & $\bullet$ & $\bullet$ & & $\bullet$ & $\bullet$ & & \\
\hline 5 & Kossiakoff et al., 2011 & 1023 & $\bullet$ & $\bullet$ & & & & $\bullet$ & $\bullet$ & \\
\hline 6 & Sage \& Rouse, 2014 & 642 & & & & $\bullet$ & $\bullet$ & $\bullet$ & & \\
\hline 7 & Wymore, A.W., 1993 & 567 & & $\bullet$ & $\bullet$ & $\bullet$ & & & & \\
\hline 8 & Weilkiens, T., 2008 & 542 & $\bullet$ & $\bullet$ & & $\bullet$ & & & & \\
\hline 9 & Keating et al., 2003 & 388 & $\bullet$ & $\bullet$ & & & $\bullet$ & & & $\bullet$ \\
\hline 10 & Martin, 1997 & 388 & $\bullet$ & $\bullet$ & & $\bullet$ & $\bullet$ & $\bullet$ & & \\
\hline 11 & Chestnut, 1967 & 374 & $\bullet$ & $\bullet$ & $\bullet$ & & & & $\bullet$ & \\
\hline 12 & Eisner, 2008 & 362 & & & & & & & $\bullet$ & $\bullet$ \\
\hline 13 & Jenkins, 1969 & 336 & $\bullet$ & $\bullet$ & & $\bullet$ & & $\bullet$ & & \\
\hline 14 & Haberfellner et al., 2019 & 305 & $\bullet$ & $\bullet$ & & & $\bullet$ & $\bullet$ & $\bullet$ & \\
\hline 15 & Hitchins, 2008 & 265 & $\bullet$ & $\bullet$ & & & $\bullet$ & & & $\bullet$ \\
\hline 16 & Honour, 2004 & 185 & $\bullet$ & & $\bullet$ & $\bullet$ & & $\bullet$ & $\bullet$ & \\
\hline 17 & Sheard \& Mostashari, 2008 & 180 & $\bullet$ & $\bullet$ & $\bullet$ & & & $\bullet$ & & \\
\hline 18 & Forsberg \& Mooz, 1992 & 153 & & $\bullet$ & $\bullet$ & & $\bullet$ & & $\bullet$ & \\
\hline 19 & Boehm et al., 2007 & 119 & & & $\bullet$ & & $\bullet$ & & & $\bullet$ \\
\hline 20 & Frank, 2000 & 128 & $\bullet$ & & $\bullet$ & $\bullet$ & & & $\bullet$ & \\
\hline 21 & INCOSE Handbook, 4th Edition, 2015 & not specified & $\bullet$ & $\bullet$ & $\bullet$ & & & & & \\
\hline 22 & Department of Defense, 2001 & not specified & $\bullet$ & & $\bullet$ & $\bullet$ & $\bullet$ & & & \\
\hline 23 & SEBok, 2019 & not specified & $\bullet$ & $\bullet$ & $\bullet$ & $\bullet$ & & & & \\
\hline & Overall Ratings in the analysis & & 18 & 15 & 13 & 11 & 9 & 9 & 9 & 4 \\
\hline
\end{tabular}

Figure 2. References analysed to identify the character of SE and identified characteristics, number of citations according to google scholar (last call 01st of December 2020). For complete list of references, please contact the author.

\subsubsection{Clustering and derived key SE-principles}

The analysis underlines the differing understanding and foci described in SE literature. There is consent, that interdisciplinary is the most relevant characteristic. However, there are only eleven references naming interdisciplinary and total system viewpoint, as the most important characteristics. Moreover, early definition of requirements is frequently mentioned as an important characteristic. With regard to the correlations between the most cited characteristics, three groups can be identified. The first group (characteristics 1, 3, and 4; no more than 2 other characteristics; references 1, 3, 16, 20, 21, and 22) describes SE as a system life cycle oriented, interdisciplinary approach focusing on the early definition of requirements. Group two (characteristics 1,2, and 6; no more than 2 more characteristics; references $2,4,5,10,13,14$, and 17) highlights interdisciplinary, a total system viewpoint and the integration of engineering and management as core characteristics of SE. The third group (characteristics 1, 2, and 5; no more than 2 other characteristics; references 4, 9, 10,14, and 15) describes SE as an interdisciplinary approach based on a total system viewpoint and a structured process. The three groups underline the duality of the system and the process domain incorporated in SE. Based on the ratings and clusters of common SE understanding six SE Principles are formulated, c.f. headlines of Table 1. The iterative approach mentioned in more current works e.g. (Keating et al., 2003; Hitchins, 2007) is integrated into the process principle. Although the number of references used for this initial analysis is limited and the analysis is highly influenced by the author's interpretations, the derived principles of SE correlate with characteristics defined in other works. For instance based on an extensive literature review Hossain et al. (2020) define interdisciplinary, holistic, requirement engineering, definition, integration and 
optimization, life cycle, and management as attributes that epitomize the fundamental core characteristics of SE. The principles in this contribution aim at giving more insights on how to organize and align design activities to pick up the core ideas of SE methodologies. To use the derived principles for the analysis and shaping of existing ecosystems of methods, 17 detailing principles where defined.

\subsection{Principles guiding SE Methodologies}

The key principles identified by the initial literature analysis highlight core ideas and objectives of different SE methodologies. To provide guidance to practitioner when shaping method ecosystems by new SE methods or adaption of existing methods, principles are needed that are more specific and pragmatic. These principles are referred to as detailing principles. In Table 1 seventeen detailing principles derived from the references, c.f. Figure 2, are presented. The principles were deduced from the processes, methods, and guidelines defined in the SE methodologies reviewed, focussing on modelbased approaches e.g. Wymore (1993), Weilkiens (2008), Friedenthal (2014) and Buede (2009), the process and activities e.g. Forsberg and Mooz (1992), Blanchard and Fabrycky (1998), Buede (2009), Martin (1997), and Kossiakoff et al. (2011) or the system theory and systems thinking fundamentals e.g. Martin (1997), Haberfellner et al. (2019), Blanchard and Fabrycky (1998), and Frank (2000) and management perspectives on SE, c.f. Emes et al. (2012) and Martin (1997). Based on the detailing principles it becomes possible to characterize existing ecosystems of methods as a basis for goal oriented implementation of SE methods, c.f. subsection 3.1.

Table 1. Principles guiding SE Methodologies derived from References given in Figure 2.

\begin{tabular}{|c|c|c|c|}
\hline$\overline{\mathbf{A}}$ & $\begin{array}{l}\text { Inte } \\
\text { Und } \\
\text { Desi }\end{array}$ & $\begin{array}{l}\text { disciplinary } \\
\text { erstanding and } \\
\text { gn }\end{array}$ & $\begin{array}{l}\text { Problem definition, problem solving and system development have to be } \\
\text { based on an interdisciplinary understanding of the system and the } \\
\text { development process. }\end{array}$ \\
\hline & A.1 & $\begin{array}{l}\text { Integrate } \\
\text { different views }\end{array}$ & $\begin{array}{l}\text { Analysis, modelling and evaluation of systems has to take into account } \\
\text { different views of the engineering domains involved. }\end{array}$ \\
\hline & A. 2 & $\begin{array}{l}\text { Use Minimal } \\
\text { Models }\end{array}$ & $\begin{array}{l}\text { For interdisciplinary collaboration, simple and commonly understandable } \\
\text { models and notations have to be used to ease decision-making and assure } \\
\text { joint problem and system understanding. }\end{array}$ \\
\hline & A.3 & $\begin{array}{l}\text { Go from Rough } \\
\text { into Details }\end{array}$ & $\begin{array}{l}\text { To reduce the complexity of problems and systems, a consequent de- } \\
\text { composition of the system and problem is required. For interdisciplinary } \\
\text { collaboration, it should be strived for overviews in a first step. }\end{array}$ \\
\hline & A.4 & $\begin{array}{l}\text { Ensure } \\
\text { Consistency }\end{array}$ & $\begin{array}{l}\text { Different models used for collaboration have to be comprehensible and } \\
\text { consistent in their information for all persons. }\end{array}$ \\
\hline
\end{tabular}

B Total System Point of Functional and physical, internal and external interfaces of the system have View to be defined based on a total system point of view.

B.1 Apply Systems For the analysis and modelling clearly defined systems and system Thinking boundaries, including different hierarchical levels have to be used.

B.2 Ensure Identity Each (system) element has be considered in its context, interactions with the environment and neighbour systems have be considered.

B.3 Structure Connections and (sub-) systems have be structured and clustered Systems and comprehensibly to support overview and ease access to information.

Information

C Lifecycle Orientation All life cycle phase of the system and the project have to be taken into account in order to integrate all stakeholder needs and assure long-lasting system functionality.

\begin{tabular}{cll}
\hline C.1 & $\begin{array}{l}\text { Consider } \\
\text { Project } \\
\text { Lifecycle }\end{array}$ & $\begin{array}{l}\text { From preparation (needs assessment for a product) to completion of the } \\
\text { project (introduction of the product), the requirements of different project } \\
\text { life phases (design, test / validation, etc.) have be taken into account. }\end{array}$ \\
C.2 $\begin{array}{l}\text { Consider } \\
\text { Product } \\
\text { Lifecycle }\end{array}$ & $\begin{array}{l}\text { From raw material extraction to recycling, requirements for the system and } \\
\text { its effects on the environment along the entire product lifecycle have to be } \\
\text { considered. }\end{array}$ \\
\hline D $\begin{array}{l}\text { Early Requirement } \\
\text { Definition }\end{array}$ & $\begin{array}{l}\text { Based on a sound problem understanding requirements have to be defined } \\
\text { in early design phases, differing between customer needs and system } \\
\text { capabilities. }\end{array}$ \\
\hline
\end{tabular}




\begin{tabular}{|c|c|c|c|}
\hline \multicolumn{3}{|c|}{$\begin{array}{ll}\text { D.1 Analyse the } \\
\text { Use Context }\end{array}$} & $\begin{array}{l}\text { The context and stakeholders of the emerging system have to be analysed } \\
\text { with regard to needs and restrictions. Derived needs have to be transferred } \\
\text { into system capabilities and requirements. }\end{array}$ \\
\hline & D.2 & $\begin{array}{l}\text { Thinking in } \\
\text { Alternatives }\end{array}$ & $\begin{array}{l}\text { Improve solutions by developing and evaluating alternative system } \\
\text { functions and structures and shifting of system boundaries. }\end{array}$ \\
\hline & D.3 & $\begin{array}{l}\text { Refer to } \\
\text { Functions }\end{array}$ & $\begin{array}{l}\text { At the forefront of problem solving is the fulfilment of a required function } \\
\text { (by one or more stakeholders). }\end{array}$ \\
\hline$\overline{\mathbf{E}}$ & \multicolumn{2}{|c|}{$\begin{array}{l}\text { Structured Process } \\
\text { and Iterations }\end{array}$} & $\begin{array}{l}\text { Design phases and activities have to be predefined to assure a structured } \\
\text { process based on a top down system design and to guide decision-making } \\
\text { as well as trigger iterations. }\end{array}$ \\
\hline & E.1 & $\begin{array}{l}\text { Decompose } \\
\text { Problems }\end{array}$ & $\begin{array}{l}\text { Complex systems and problems should be broken down into manageable } \\
\text { sub-problems. Interfaces have to be defined when decomposing. }\end{array}$ \\
\hline & E.2 & $\begin{array}{l}\text { Proceed } \\
\text { Iteratively }\end{array}$ & $\begin{array}{l}\text { Inadequate solutions and understandings of problems have to be improved } \\
\text { by iterations (analysis, synthesis, evaluation). }\end{array}$ \\
\hline & E.3 & $\begin{array}{l}\text { Progress } \\
\text { Discursively }\end{array}$ & $\begin{array}{l}\text { Goals have to be planned and reviewed after each design action and the } \\
\text { resulting information have to be adjusted if necessary. }\end{array}$ \\
\hline \multirow[t]{3}{*}{$\mathbf{F}$} & \multicolumn{2}{|c|}{$\begin{array}{l}\text { Integrate } \\
\text { Engineering and } \\
\text { Management }\end{array}$} & $\begin{array}{l}\text { Planning, organizing, control and directing of activities have to take into } \\
\text { account and balance technical, project and economic aspects. }\end{array}$ \\
\hline & F.1 & $\begin{array}{l}\text { Evaluate Risk } \\
\text { Continuously }\end{array}$ & $\begin{array}{l}\text { Assess the risk with regard to technical and economic criteria based on the } \\
\text { achieved project results. }\end{array}$ \\
\hline & F.2 & $\begin{array}{l}\text { Realise } \\
\text { Verification }\end{array}$ & $\begin{array}{l}\text { Verification of systems, subsystems and modules have to be planned at the } \\
\text { early beginning of the engineering process. Results of verification have to } \\
\text { be used to control the project. }\end{array}$ \\
\hline
\end{tabular}

\section{SHAPING METHOD ECOSYSTEMS - INSIGHTS FROM WORKSHOPS}

The SE Principles proposed in section 2 were used in a series of workshops aiming to implement SE methodologies into the development process of an automotive manufacturer. A major objective was to sensitize engineers and manager from different departments and with different previous knowledge on core ideas of SE. Moreover, the identification of fields to integrate specific SE methods from the individual viewpoint of engineers and managers was a main objective. Therefore, the workshop participants were guided through a structured process, c.f. Figure 3.

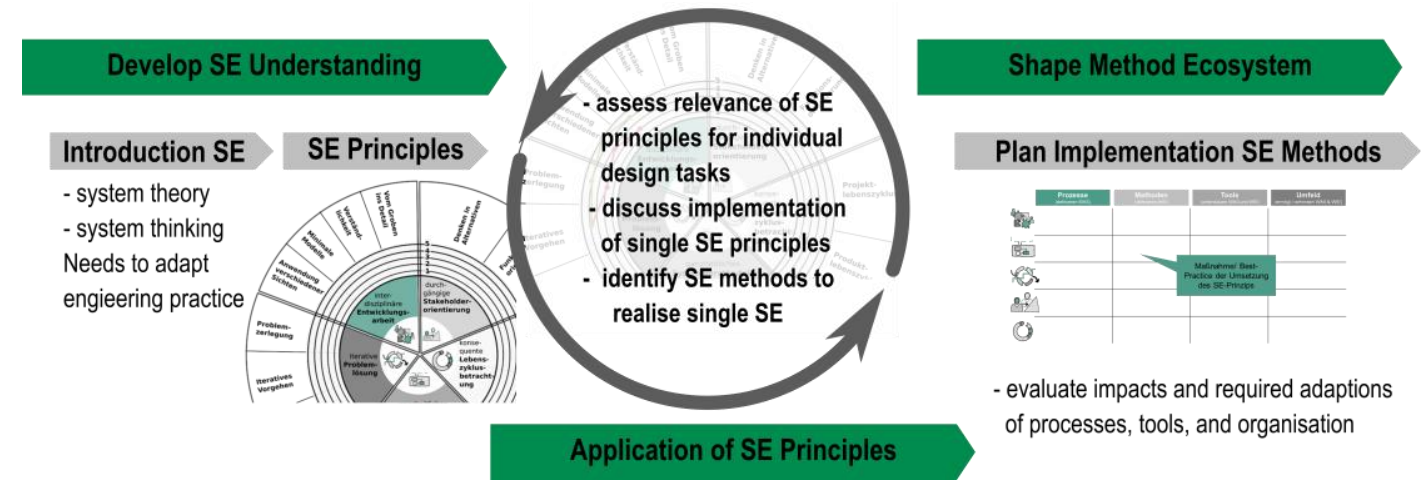

Figure 3. Procedure of the workshop to apply SE Principles.

Therefore, in a first step fundamentals of system theory and system thinking were introduced highlighting the necessity to change best practices (processes, methods, and tools) currently used in engineering. In addition, main interactions between processes, methods, tools, and organization were introduced based on the PMTE-paradigm of Martin (1997). In a second step, the SE Principles were introduced and explained by giving different design activities and first examples for SE methods to realize the principles. Based on these inputs the participants were ask to evaluate the relevance and current state of the SE Principles with direct reference to their specific design tasks and roles in the existing engineering processes. Here a broad range of activities was covered including for instance evaluation of functional safety, function definition, system architecture definition, and requirements 
management. The gaps between current state and relevance of the SE Principles were discussed and SE methods were identified to address the deficits. To plan integration of new SE methods, required adaptions of processes (e.g. required inputs), tools, and organisations (e.g. competencies and responsibilities) were determined by the participants. Figure 3 summarizes the workshop procedure.

\subsection{Tools and Procedure to Assess SE Principles and Identify SE Methods}

To support assessment of the SE Principles the descriptions and a radar chart were provided to the workshop participants. The radar chart, see Figure 4.A, was used to evaluate relevance and current state of the SE Principles for the individual design activities the participants are involved in in the current design process. Therefore, the relevance (green line) and current implementation (red line) were assessed based using a scale from one (very low relevance/ implementation) up to five (very high relevance/ implementation). The individual assessment allows to gain a task and process specific understanding of SE methodologies and the intended adaption of the existing ecosystem of methods. The individual assessment was discussed with workshop attendees and experts from the field of SE to address both, the understanding of the principles and the identified gaps between relevance and current implementation. Based on the identified gaps suitable methods to overcome these were proposed focussing on a first set of methods introduced in the workshops and methods known by the participants. To plan the implementation of the proposed new methods, a matrix was provided, c.f. Figure 4 B. Herein, required adaptions with regard to processes, tools and organisation were documented. Based on the selected SE methods like structured stakeholder analysis measures were discussed and documented.

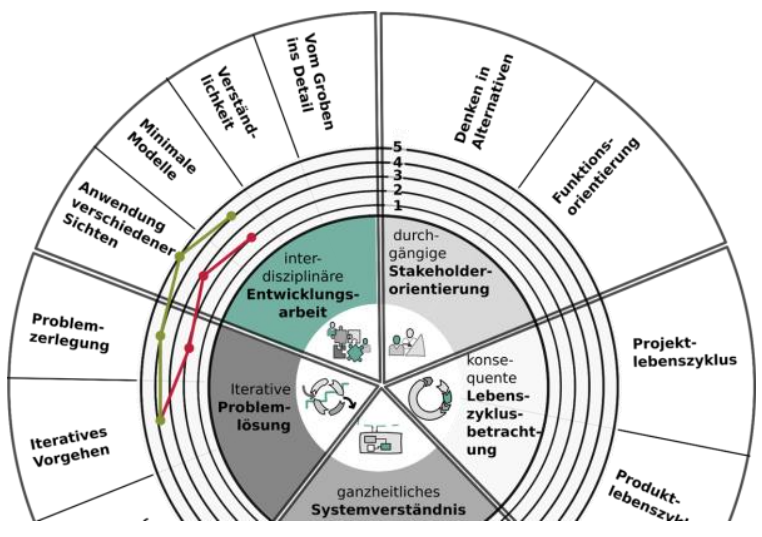

A. Radar chart to assess relevance and implementation of SE Principles in specific design activities

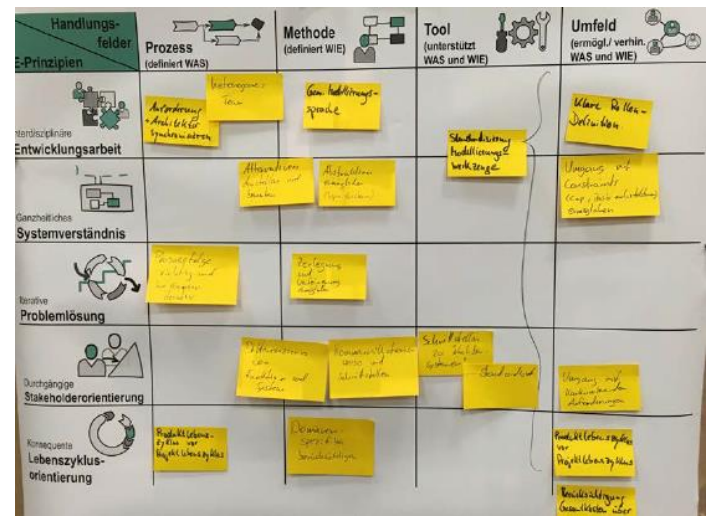

B. Matrix to plan implementation of SE methods and adaptions of processes, tools, and organisation

Figure 4. Tools provided to assess SE Principles and plan SE method implementations

\subsection{First Insights from Workshops in Industry}

Overall, four workshops with a total number of 74 participants were conducted using the procedure and tools introduced. Within these workshops, first insights on the applicability and usefulness of the proposed SE Principles and workshop tools were gained. Therefore, subsequent to the workshops an evaluation was carried out using a short questionnaire to capture the individual previous knowledge in the field of SE and about SE methods, comprehensibility and traceability of the provided SE Principles, usefulness of the SE Principles to identify new methods, and individually gained knowledge about SE. The five evaluation criteria were rated using a scale from one to five. The results of the evaluation are summarized in Table 2.

Based on the evaluation and additional feedback provided by the participants it can be stated, that the principles are useful to gain an overall and activity specific understanding of SE. The participants state, that most of the principles are easy to understand and can be transferred to the individual engineering context. However, it appears to be challenging to identify both existing methods and new SE methods based on the principles provided. Since the knowledge about SE methods was limited, the participants in many cases refer to the methods introduced in the first part of the workshops. 
Table 2: Overview of the criteria and ratings of the evaluation after the workshops

\begin{tabular}{|c|c|}
\hline Evaluation Criteria & Ratings (1 to 5) \\
\hline Individual knowledge about Systems Engineering & Average: 2,1 \\
\hline Assess your individual knowledge about SE before attending the workshop & S. Deviation: 0,612 \\
\hline Individual knowledge about methods used in Systems Engineering & Average: 1,6 \\
\hline Assess your knowledge about SE methods before attending the workshop & S. Deviation: 0,346 \\
\hline $\begin{array}{l}\text { Proposed SE Principles } \\
\text { How comprehensible and traceability are the introduced SE Principles to you? }\end{array}$ & $\begin{array}{l}\text { Average: } \mathbf{4 , 0} \\
\text { S. Deviation: } 0.461\end{array}$ \\
\hline $\begin{array}{l}\text { Use of SE Principles to identify new methods } \\
\text { Was it possible to identify new methods based on the analysis of the SE } \\
\text { Principles for your design activity? }\end{array}$ & $\begin{array}{c}\text { Average: } \mathbf{3 , 2} \\
\text { S. Deviation: } 0,287\end{array}$ \\
\hline $\begin{array}{l}\text { Gained knowledge about Systems Engineering } \\
\text { Assess the individual knowledge about Systems Engineering and method } \\
\text { implementation gained in the workshop. }\end{array}$ & $\begin{array}{c}\text { Average: } \mathbf{3 , 7} \\
\text { S. Deviation: } 0,386\end{array}$ \\
\hline
\end{tabular}

In addition, within the workshops different approaches, known by participants were extensively discussed without sticking to the strict differentiation of processes, methods, and tools. In order to foster the needed distinction the matrix, c.f. Figure $4 \mathrm{~B}$, was proven helpful. Using this structure, the participants were able to identify needed changes and extensions based on the identified SE methods. A more detailed evaluation of the applicability and usefulness of the introduced SE Principles and workshop tools as well as the impact on the overall process of SE implementation will be investigated in future projects with a focus on single SE activities like system architecture definition and evaluation.

\section{LIMITATIONS, DISCUSSION AND FURTHER RESEARCH}

The research presented aims at supporting the implementation of SE methodologies in existing organisations. Instead of focussing on the research and implementation of single methods, SE Principles proposed to describe the core ideas and objectives of SE methodologies. The principles serve to analyse the existing and shape the future ecosystem of methods including required adaptions of processes, tools, and organisation. The SE Principles are derived from an initial literature review and checked for validity by relating them to existing attributes of SE found in literature. The first insights gained from workshops in industry prove the general applicability of SE Principles to identify new methods for realize the SE Principles. However, no detailed evaluation has been carried out yet. This missing evaluation and the limited number of references as well as the analysis method used in the literature review, c.f. section 2.1.1 limit the validity of the results presented. Moreover, the insights from the first workshops highlight the need for a more detailed and comprehensive research and introduction on SE methods to overcome the missing knowledge of engineers in practice. Future work will focus on three fields:

- Extended analysis and consolidation of the SE Principles using methods from data mining and clustering.

- More detailed investigation of methods to analyse and describe the ecosystem of methods in the field of applied SE including the integration of required competencies.

- Refinement of the workshop concept and tools to enable engineers for analysing and shaping their ecosystem of methods.

Future research will focus on building up a knowledge database for SE methods based of previous works of the author (Bavendiek et al., 2014). Here a focus will be on the access and selection process of methods based on the SE Principles introduced as well as an adaptive structure to describe the methods.

\section{ACKNOWLEDGEMENT}

The research presented is part of the project RePASE - Reflective Process Development and Adaptation in Advanced Systems Engineering. This project is funded by the German Federal Ministry of Education and Research (BMBF) within the Program "Innovations for Tomorrow's Production, Services, and Work" (02J19B149) and managed by the Project Management Agency Karlsruhe (PTKA). The author is responsible for the contents of this publication. 


\section{REFERENCES}

Bavendiek, A., Inkermann, D. and Vietor, T. (2014), "Konzept zur Methodenbeschreibung und - auswahl auf Basis von Kompetenzen und Zusammensetzung von Entwicklungsteams", in Symposium Design for X 2014, pp. $215-226$.

Birkhofer, H., Kloberdanz, H., Sauer, T. and Berger, B. (2002), "Why methods don't work and how to get them to work", Zielona Gora.

Blanchard, B.S. and Fabrycky, W.J. (1998), Systems engineering and analysis, Prentice Hall international series in industrial and systems engineering, 3. ed., Prentice Hall, Upper Saddle River, NJ.

Buede, D.M. (2009), The engineering design of systems: Models and methods, Wiley series in systems engineering and management, 2. ed., Wiley, Hoboken, NJ.

Emes, M.R., Smith, A., James, A.M., Whyndham, M.W., Leal, R. and Jackson, S.C. (2012), "8.1.2 Principles of Systems Engineering Management: Reflections from 45 years of spacecraft technology research and development at the Mullard Space Science Laboratory", INCOSE Int. Sym., Vol. 22 No. 1, pp. 1069-1084.

Estefan, J.A. (2008), Survey of Model-Based Systems Engineering (MBSE) Methodologies: Rev. B.

Forsberg, K. and Mooz, H. (1992), "The Relationship of Systems Engineering to the Project Cycle", Engineering Management Journal, Vol. 4 No. 3, pp. 36-43.

Forsberg, K. and Mooz, H. (1995), “4.4.4 Application of the 'Vee' to Incremental and Evolutionary Development”, INCOSE International Symposium, Vol. 5 No. 1, pp. 848-855.

Frank, M. (2000), "Engineering systems thinking and systems thinking”, Systems Engineering, Vol. 3 No. 3 , pp. $163-168$.

Friedenthal, S. (2014), A practical guide to SysML: The systems modeling language, Third edition, Morgan Kaufman, Waltham, MA.

Gausemeier, J., Dumitrescu, R., Steffen, D., Czaja, A., Wiederkehr, O. and Tschirner, C. (2015), Systems Engineering in Industrial Practice, Paderborn.

Gericke, K., Eckert, C., Campean, F., Clarkson, P.J., Flening, E., Isaksson, O., Kipouros, T., Kokkolaras, M., Köhler, C., Panarotto, M. and Wilmsen, M. (2020), "Supporting designers: moving from method menagerie to method ecosystem", Design Science, Vol. 6, p. 49.

Gericke, K., Eckert, C. and Stacey, M. (2017), "What do we need to say about a design method?", in Maier, A., Kim, H., Oehmen, J., Salustri, F., Škec, S. and Kokkolaras, M. (Eds.), Design theory and research methodology, DS, Curran Associates Inc, Red Hook, NY, pp. 101-110.

Haberfellner, R., Weck, O.L. de and Fricke, E. (2019), Systems Engineering: Fundamentals and applications, Birkhäuser, Basel.

Hitchins, D.K. (2007), Systems engineering: A 21 st century systems methodology, Wiley series in systems engineering and management, John Wiley, Chichester, West Sussex, England, Hoboken, NJ.

Hossain, N.U.I., Jaradat, R.M., Hamilton, M.A., Keating, C.B. and Goerger, S.R. (2020), “A Historical Perspective on Development of Systems Engineering Discipline: A Review and Analysis", Journal of Systems Science and Systems Engineering, Vol. 29 No. 1, pp. 1-35.

Huldt, T. and Stenius, I. (2019), "State-of-practice survey of model-based systems engineering”, Systems Engineering, Vol. 22 No. 2, pp. 134-145.

Keating, C., Rogers, R., Unal, R., Dryer, D., Sousa-Poza, A., Safford, R., Peterson, W. and Rabadi, G. (2003), "System of systems engineering", IEEE Engineering Management Review, Vol. 36 No. 4, p. 62.

Kossiakoff, A., Sweet, W.N., Seymour, S.J. and Biemer, S.M. (2011), Systems Engineering: Principles and practice, Wiley series in systems engineering and management, Vol. 67, 2nd ed., Wiley-Interscience, Hoboken, N.J.

Lamm, J.G. and Weilkiens, T. (2010), "Funktionale Architekturen in SysML", in In M. Maurer and S.-O. Schulze (eds.), Tag des Systems Engineering 2010 Carl Hanser Verlag, München, Germany, November 2010, pp. 109-118.

Lohmeyer, Q. and Albers, A. (2012), “Advanced systems engineering - Towards a model-based and humancentered methodology” in Int. Sym. on Tools and Methods of Competitive Engineering TMCE 2012.

Martin, J.N. (1997), Systems engineering guidebook: A process for developing systems and products, Systems engineering series, CRC Press, Boca Raton.

Sheard, S.A. and Mostashari, A. (2009), "Principles of complex systems for systems engineering”, Systems Engineering, Vol. 12 No. 4, pp. 295-311.

Walden, D.D., Roedler, G.J., Forsberg, K., Hamelin, R.D. and Shortell, T.M. (Eds.) (2015), Systems engineering handbook: A guide for system life cycle processes and activities, 4. edition, Wiley, Hoboken, NJ.

Wallace, K. (2011), "Transferring design methods into practice”, in Birkhofer, H. (Ed.), The Future of Design Methodology, Springer-Verlag, London, pp. 239-248.

Weilkiens, T. (2008), Systems Engineering with SysML/UML: Modeling, Analysis, Design, The MK / OMG Press, 1. Edition, Elsevier professional.

Wymore, A.W. (1993), Model-Based Systems Engineering, Systems Engineering Ser, Chapman and Hall/CRC, Boca Raton. 